\title{
Inauguration of the XXXI Mexican Congress of Cardiology
}

\author{
Santiago de Querétaro, Mexico, 2019 \\ Inauguración del XXXI Congreso Mexicano de Cardiología \\ Dr. Pedro Iturralde-Torres* \\ President of the Mexican Society of Cardiology
}

Distinguished Minister Secretary of the Interior Olga Sánchez Cordero, members of the Head Table, cardiologist colleagues, specialists, nurses, specials guests, ladies and gentlemen.

On behalf of the Board of Directors of the Mexican Society of Cardiology 2018-2020, I cordially express to all present the most affectionate welcome to our thirty-first Mexican Congress of Cardiology.

The Mexican Society of Cardiology has reached 84 years of existence and, since its birth, every two years it congregates its members in its national congresses with the purpose to spread knowledge on Cardiology current issues.

I gladly comply with the duty to remember and pay tribute to our founder and honorary president, Professor Ignacio Chávez, an emblematic leading figure of medicine, education, culture and humanism in the $20^{\text {th }}$ century.

Our recognition to the former presidents for their commitment and dedication to achieve the advance of our society. Every one of them, at the time, built and consolidated with their work a rock-solid academic platform of the highest scientific level.

"The achievements of a scientific society are the sum of the contributions of its members. Its projection and scope are based on joint effort, on unified far-sighted vision and on the conjunction of wills." This is how the Society continues its constant academic work to the benefit of Mexican cardiologists.
In Mexico, as in the rest of the world, cardiovascular diseases represent the first cause of death. Last year, 130,000 cases were reported in the country, out of which 100,000 were related to acute coronary syndrome. Therefore, cardiovascular diseases cause more deaths than cancer.

The most important cardiovascular risk factors are obesity and overweight, especially in children, and in this regard Mexico ranks first in the world. Diabetes and high blood pressure, which are suffered by more than 30 million Mexicans, as well as increased cholesterol, smoking and sedentary lifestyle, have contributed for the acute myocardial infarction mortality rate to be three times higher than the average in the countries of the Organization for Economic Cooperation and Development in patients older than 45 years, and it is therefore essential to take primary prevention measures to prevent that in the next decades one out of every two Mexicans die from heart diseases.

This implies a global challenge, and hence the importance of the " $25 \times 25$ " initiative of the World Heart Federation and the World Health Organization, which involves the commitment to reduce cardiovascular disease mortality by $25 \%$ for the year 2025 . Hence the importance of cardiology societies for this project to succeed.

During the $31^{\text {st }}$ Mexican Congress of Cardiology we will have the participation of more than 400 prominent

\section{Correspondence:}

${ }^{*}$ Dr. Pedro Iturralde Torres

E-mail: pedroi@yahoo.com

DOI: 10.24875/ACME.M20000083
Date of reception: 27-11-2019

Date of acceptance: 28-11-2019
Available online: 09-02-2020 Arch Cardiol Mex (Eng). 2020;90(1):1-3 www.archivoscardiologia.com ND license (http://creativecommons.org/licenses/by-nc-nd/4.0/) 
national professors, all of them certified by the corresponding specialty council, and more than 100 excellent international professors.

Along with the Mexican congress, the $2^{\text {nd }}$ Inter-American Congress of Heart Failure will be carried out simultaneously, with important and relevant topics in the areas of pulmonary hypertension and heart failure. In addition, the $3^{\text {rd }}$ Mexican Congress of Cardiovascular Rehabilitation, Prevention and Sports Cardiology, which will include valuable concepts and skills that in daily practice will accompany the patient with heart disease during convalescence until his/her prompt and complete reincorporation.

The academic program consists of 426 hours, which make up a total of 208 modules with 537 sessions, where all the cardiology and nursing high specialties will be included, distributed in plenary sessions, keynote speeches, symposiums, panel discussions, clinical case presentations, debates and more than 80 hours of pre-congress courses, workshops and social, cultural and sports activities.

More than 20 joint sessions will be held with sister societies, such as the Inter-American Society of Cardiology, the Spanish Society, the Brazilian Society, the Argentinian Society and Federation, the Paraguayan Society, the American College of Cardiology, the American Heart Association and the European Society of Cardiology.

The opening conference of the congress bears the title "Myocardial regeneration strategies", and will be presented by Dr. Victor Dzau, President of the Academy of Medicine of the United States of America, who graces us with his presence.

Various techniques of coronary, structural, congenital heart disease, cardiac surgery, electrophysiology and heart failure intervention, as well as multiple cardiovascular imaging and cardiology nursing techniques will be addressed during these four days by experts who will present their experiences and international latest news on these topics.

It is indeed a great pride and a stimulus for us having the presence of 400 young doctors and cardiology residents who will present their own research works, with 389 oral and 282 electronic poster presentations.

All this within the framework of the emblematic city of Santiago de Querétaro, which generously hosts our congress. The state of Querétaro is endowed with a natural and cultural wealth that allows us knowing our roots. It preserves four world heritage sites and six "magical towns", and owing to its zone of monuments in the historic center, in 1996 it was declared world cultural heritage site by the United Nations Educational, Scientific and Cultural Organization.

Querétaro also represents the valuable past and the thriving present. Valuable past because it has been a protagonist in the history of Mexico in transcendental events, it was strategic for the troops during the War of Independence and the Mexican Revolution; and it was at the Great Theater of Iturbide, today Theater of the Republic, on February 5, where the 1917 Constitution was signed.

Its present is thriving because it is a modern city and one of the cities with the fastest industrial growth in Mexico. Today, it receives us with the hospitality that characterizes its people and gives us the warmest welcome.

"The groups of people who attend congresses change, just like the cities that hostour event change. But the message essentially remains the same. Inasmuch as it reflects the truth, its value remains immutable. That is why it doesn't matter that, in one way or another, the message is repeated, as long as it preserves the same strength of reality and truth."

In the words of Professor Chávez, "A scientific congress takes on value if we attend willing to submit our ideas and our findings to the criticism of others, in order to benefit from it. A congress should be a dialogue between researchers who seek the truth, a forum for discussions with a spirit of honest confrontation of ideas and with an open mind to admit new truths."

"The first obligation of every doctor is to every day know more in order to better serve every day. It is of no use that medicine advances if patients cannot reach its benefits. Top scientific disciplines and proper use of great advances are for patients their true table of salvation, and in addition they are like the oxygen of the soul for men who devote themselves to the cultivation of their knowledge."

The motto (plus est en toi) "There is more in you" was adopted by unanimous vote by the members of the Mexican Society of Cardiology in 1979, since it was the motto of its founder. By adopting his motto, the Society members not only claim that they have faith in man and believe in his destiny. A goal is also pointed out, an ideal is set: excellence, which implies following the goal regardless of obstacles and opening roads when they don't exist. Thus, the ideal of our Society is excellence in science and humanism.

The need to teach, the desire to share knowledge and his experience, the passion for learning medicine and transmitting all that he learned was what drove Dr. Ignacio Chávez to become an illustrious pedagogue, a builder of teaching programs, a revolutionary director in the Faculty of Medicine and an exceptional 
rector. But more than that, it made him a guide, an example for younger generations, and allowed him to carve, polish and shape superior persons who are his best work and full guarantee of his transcendence.

Being a doctor, as taught by the Professor, is the result of an indeclinable vocation, of an internal call that is accepted without restrictions, in an entire, absolute and permanent way.

In the commemoration of the fortieth anniversary of Professor Ignacio Chavez sad passing, let his memory accompany us in our congresses and may his spirit always live among us. 